\title{
Visualization of various working fluids flow regimes in gravity heat pipe
}

\author{
Patrik Nemec ${ }^{1, *}$ \\ ${ }^{1}$ University of Zilina, Faculty of Mechanical Engineering, Department of Power Engineering, Univerzitna 8215/1, 01026 Zilina, Slovakia
}

\begin{abstract}
Heat pipe is device working with phase changes of working fluid inside hermetically closed pipe at specific pressure. The phase changes of working fluid from fluid to vapour and vice versa help heat pipe to transport high heat flux. Amount of heat flux transferred by heat pipe, of course depends on kind of working fluid. The article deal about visualization of various working fluids flow regimes in glass gravity heat pipe by high speed camera and processes casing inside during heat pipe operation. Experiment working fluid flow visualization is performed with two glass heat pipes with different inner diameter $(13 \mathrm{~mm}$ and 22 $\mathrm{mm}$ ) filled with water, ethanol and fluorinert FC 72. The working fluid flow visualization explains the phenomena as a working fluid boiling, nucleation of bubbles, and vapour condensation on the wall, vapour and condensate flow interaction, flow down condensate film thickness on the wall occurred during the heat pipe operation.
\end{abstract}

\section{Introduction}

The thermosiphon (gravity heat pipe) is shown in figure 1. The bottom is a heating (evaporation) section, the middle an adiabatic section, and the upper part a condensation section.

A small quantity of liquid is placed in a tube from which the air is then evacuated and the tube sealed.

The lower end of the pipe is heated, this causing that the vapour flows from the bottom to the condensation section where it is cooled and condensed into liquid. Then the liquid flows downwards along the wall as a very thin film. However, liquid plugs may form at high heat input. This entire cycle repeats in heat pipe again and again.

The Thermosiphon works on both conduction and convection mechanism. The heat from the heat source is transferred to the thermosiphons through conduction and inside thermosiphon heat convection occurs [1].

Since the latent heat of evaporation is large, considerable quantities of heat can be transported with a very small temperature difference from end to end. Thus, the structure will also have a high effective thermal conductance.

One limitation of the basic thermosiphon is that in order for the condensate to be returned to the evaporator region by gravitational force, the evaporation section must be situated at the lowest point [2].

The amount of heat that can be transported by these systems is normally several orders of magnitude greater than pure conduction through a solid metal [3].

A thermosiphon needs only a temperature difference to transfer large amount of heat, and are widely used in various areas of industry, such as chemical engineering, thermal engineering or thermal management systems with limited space applications and other heat recovery systems.

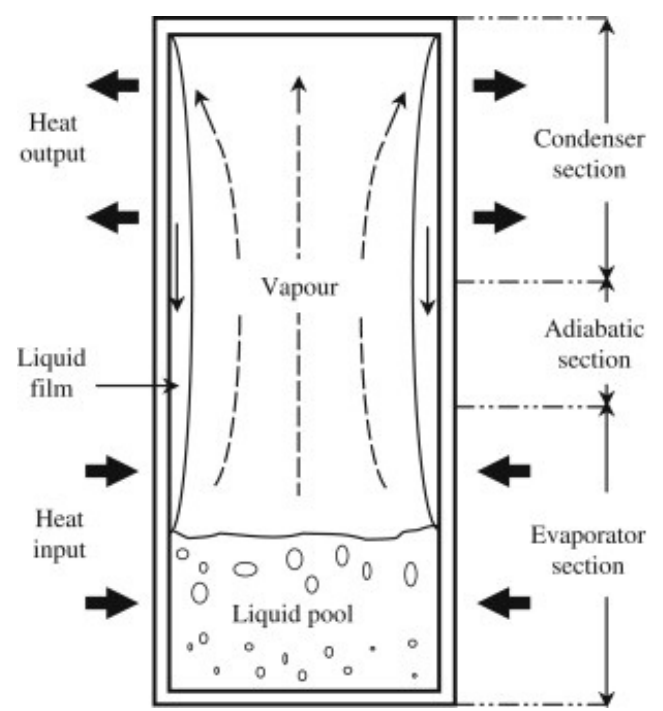

Fig. 1. Working principle of the Thermosiphon [4]

\section{Boiling and condensation}

The theory of boiling is complex and not yet fully understood. The boiling process depends on factors such as mass flow, vapour content and the temperature difference between the working fluid and the heating surface. The available research is based on empirical experiments on smooth tubes. However, the processes of evaporation could be explained by a combination of the available research on boiling and flow regimes $[5,6]$.

*Corresponding author: patrik.nemec@,fstroj.uniza.sk 


\subsection{Boiling}

The heat transfer coefficient for pool boiling has a characteristic curve shown in figure 2 that displays heat flux versus the temperature difference between the evaporating working fluid and heating surface. As the temperature difference increases, the energy flow per heat transfer area $(\mathrm{kW} / \mathrm{m} 2)$ will increase until an unstable maximum value for heat transfer is reached, the critical heat flux. At this point, vapour will form to such an extent that it hinders contact between the liquid of working fluid and the heat transfer area. As the temperature difference increases, a continuous gas film will form and the heat flux will reach a minimum. In the figure 2 are shown different boiling regimes.

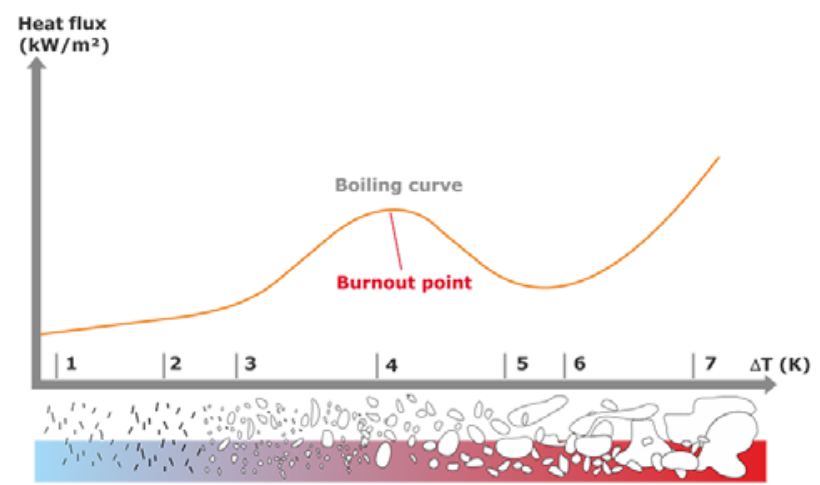

Fig. 2. Boiling regimes [7]

Free convection evaporation: Heat is transferred between the wall and the working fluid without bubble formation. The liquid close to the surface wall becomes slightly superheated and evaporates in the interface between liquid and gas.

Sub-cooled nucleate boiling region: Heat transfer between the wall and the working fluid is sufficiently large to create bubbles, but they collapse in contact with the liquid bulk.

Nucleate boiling region: This is the most important boiling region for technical applications. The temperature difference required to enter this region is approximately $3 \mathrm{~K}$. Superheated liquid overcomes the surface tension, forming unstable vapour bubbles that collapse in contact with the sub-cooled liquid of working fluid. The additional turbulence caused by forming and collapsing bubbles increases the heat transfer. The heat transfer increases as the temperature difference between the working fluid and the heating surface wall increases to reach a maximum critical heat flux at the burnout point.

Partial film boiling: Increasing the temperature difference further, beyond the burnout point, will cause the working fluid to evaporate too quickly to allow new liquid of working fluid access to the heat transfer surface. The partial vapour blanket acts as insulation, causing the heat transfer coefficient to drop greatly and reducing the overall heat flux. This is an unstable region that should be avoided, because performance is uncertain and may fluctuate substantially.

Complete film boiling: With a very high temperature difference, a stable film of working fluid vapour will form on the heat transfer area. The film will act as an effective insulation layer hindering any direct contact between the heating surface and the liquid working fluid. Although the heat transfer coefficient reaches a minimum here, this evaporation region is preferable over the unstable partial film-boiling region, because predictions of the heat transfer coefficient are more reliable.

\subsection{Condensation}

Condensation is the phase transformation from vapour to liquid state. It may be carried in a space or on a solid surface and is provided with a heat and mass transfer. The heat pipe efficiency is supported by high rates of heat transfer during the condensation. The condensation on a solid surface can occur in the two different ways shown in figure 3 as a film condensation or dropwise condensation.

When the film condensation occurs, the condensate is form in a continuous liquid film that covers and wets the solid wall cold surface. The liquid film flows down the surface under gravity or other forces (e.g. capillarity). Heat transfer to the solid surface extends through the liquid film [8].

When the dropwise condensation occur, the working fluid vapour reach the wall cold surface, reduces its energy and causing the working fluid liquefaction and droplets formation on the cold surface that grow with direction of the vapour condensation. The small neighbour's drops are collecting to the bigger drops until they are tearing down from the surface by the gravity or other forces. As drops are flow down the wall, they leaving clean surface where condensation can proceed [9].

The heat transfer coefficient of the dropwise condensation is 10 times larger than the film condensation, but its duration is short and from this reason is difficult usable in practice. If the dropwise condensation has been continuous or if the thickness of the liquid film has been reduced can be achieved increasing heat transfer coefficient [10].

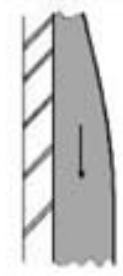

a)

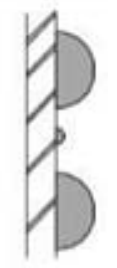

b)
Fig. 3. Condensation regimes: a) Film condensation, b) Dropwise condensation [11]

\section{Experiments}

Experiments deal about flow visualization of working fluids (water, ethanol and fluorinert FC 72) in glass gravity heat pipes with inner diameter 13 and $22 \mathrm{~mm}$ and total length $500 \mathrm{~mm}$. In the figure 4 is shown positioning of the experimental apparatus. The working 
fluid flow inside the glass heat pipe placed on the heat source with heat output regulator was scanned by high speed video camera. The visualization of the working fluid flow in heat pipes can be helpful in solution or CFD simulation of the flow dynamics or heat and mass transfer of the heat pipes $[12,13]$.

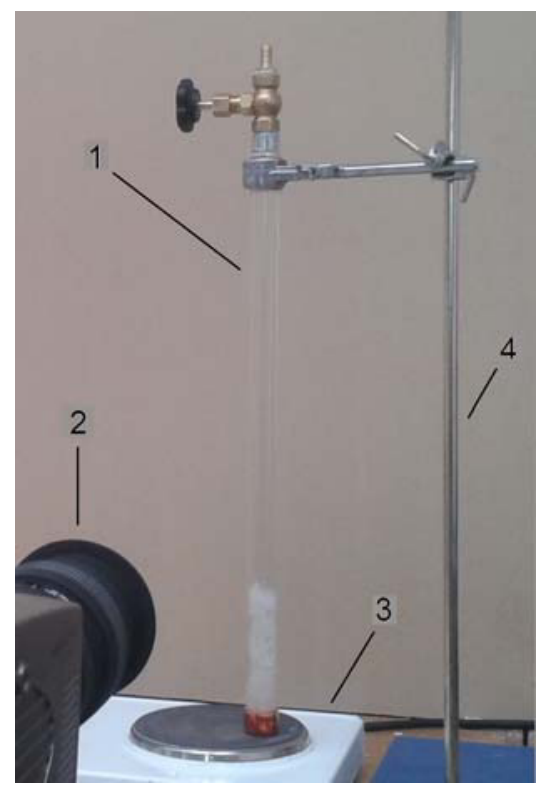

Fig. 4. Measuring setup: 1 - thermosiphon, 2 - video camera, 3 - heat source, 4 - stand

\subsection{Heat pipe construction}

In the figure 5 are containers of gravity heat pipes manufactured for experiment of working fluid visualization. The body of heat pipes is created form borosilicate glass tube. The borosilicate glass is suitable for laboratory use because is more resistant to thermal shock than others glass. It has a smoother transition between temperatures, and can even withstand different temperatures at the same time. On the bottom is $\mathrm{Cu}$ cap and on the top is filling and closing valve.

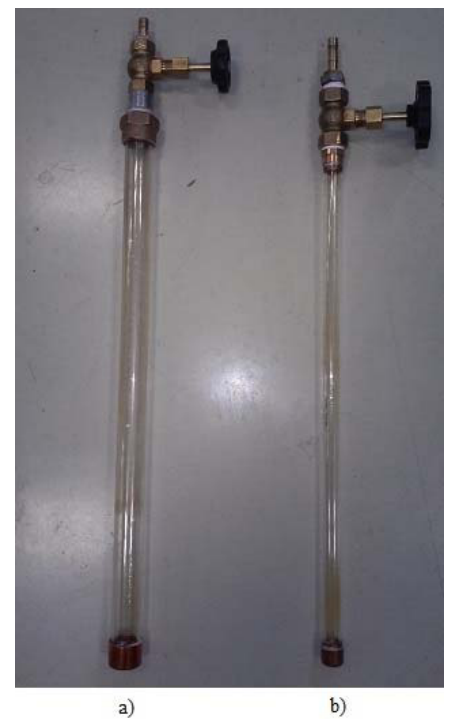

Fig. 5. Glass containers of gravity heat pipes: a) Inner diameter $13 \mathrm{~mm} \mathrm{~b}$ ) Inner diameter $22 \mathrm{~mm}$
The heat pipes manufacturing was performed by method of working fluid evaporation. This method covers filling the total volume of heat pipe with working fluid and then evaporation of working fluid to $20 \%$ of heat pipe. This method guaranty that inside heat pipe is only pure working fluid and no air is inside.

\subsection{Working fluid flow visualization}

In the figures $6,7,8,9,10$ and 11 are shown two-phase flow regimes of working fluid (water, ethanol and fluorinert FC 72) in gravity heat pipe at evaporator temperature $105{ }^{\circ} \mathrm{C}$ scanned by high speed video camera.

In the figure 6 are shown evaporation and condensation sections of glass gravity heat pipe with inner diameter $13 \mathrm{~mm}$ and water working fluid. In the figure $6 \mathrm{a}$ is shown film boiling and creating big bubbles of the working fluid on bottom heat pipe evaporator section. On the top is seen as a vapour pushes the liquid to the adiabatic section. In the figure $6 \mathrm{~b}$ is shown dropwise condensation of the working fluid on the condensation section surface. The small droplets are collected to the big drops and they flow down to the evaporator section due to gravitation action. Thus is created free space for a new dropwise condensation on the clear surface.

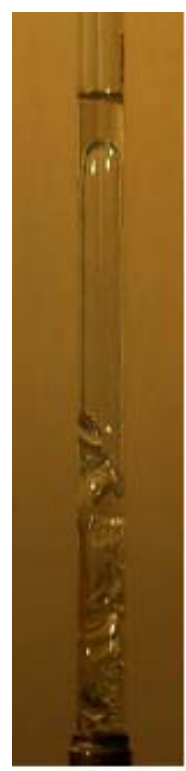

a)

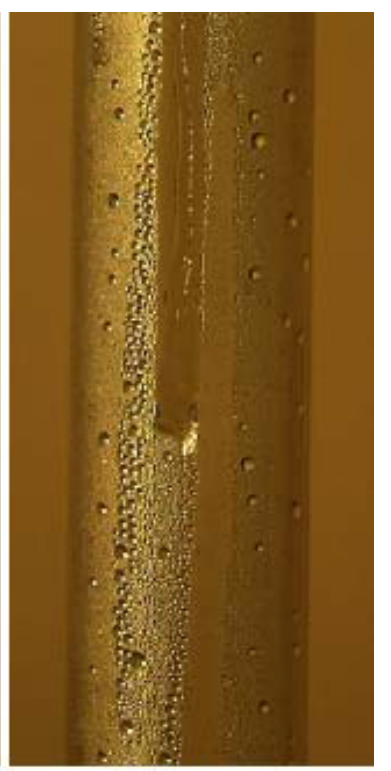

b)
Fig. 6. Glass gravity heat pipe - inner diameter $13 \mathrm{~mm}$, working fluid water: a) Evaporation section b) Condensation section.

In the figure 7 are shown evaporation and condensation sections of glass gravity heat pipe with inner diameter $22 \mathrm{~mm}$ and water working fluid. In the figure $7 \mathrm{a}$ is shown film boiling and creating big bubbles of the working fluid on bottom heat pipe evaporator section. It is similar action as in the heat pipe with inner diameter $13 \mathrm{~mm}$, but in this case liquid is not pushes by vapour to the adiabatic section so high. This may cause bigger diameter of heat pipe. In the figure $7 \mathrm{~b}$ is shown dropwise condensation of the working fluid on the 
condensation section surface. In this case this action is same as at heat pipe with inner diameter $13 \mathrm{~mm}$.

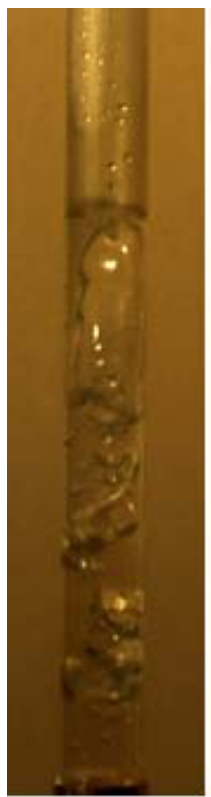

a)

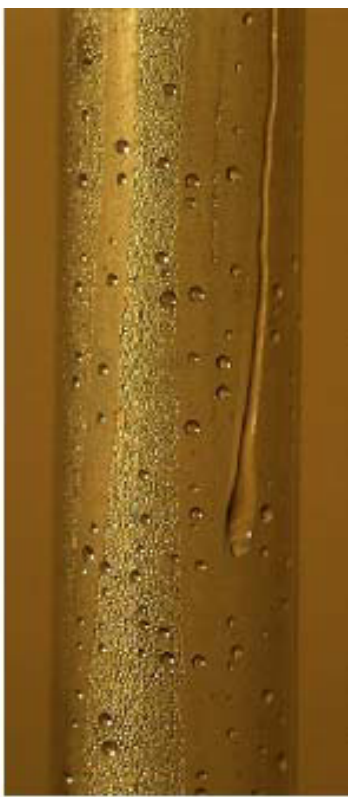

b)
Fig. 7. Glass gravity heat pipe - inner diameter $22 \mathrm{~mm}$, working fluid water: a) Evaporation section b) Condensation section.

In the figure 8 are shown evaporation and condensation sections of glass gravity heat pipe with inner diameter $13 \mathrm{~mm}$ and ethanol working fluid. In the figure $8 \mathrm{a}$ is shown pool boiling of the working fluid in whole evaporator section. In the figure $8 \mathrm{~b}$ is shown condensation section. The heat from evaporator to condenser was transferred well but there was observed even not dropwise condensation either film condensation of the working fluid in this kind of heat pipe.

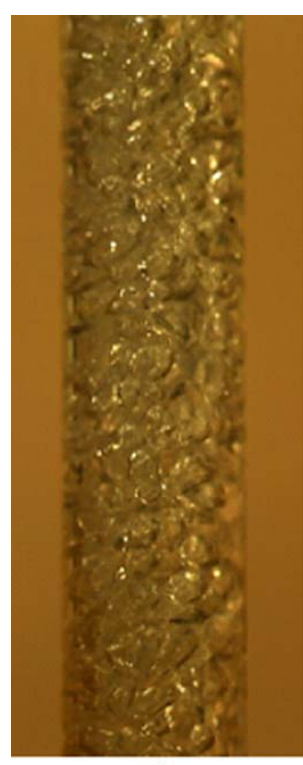

a)

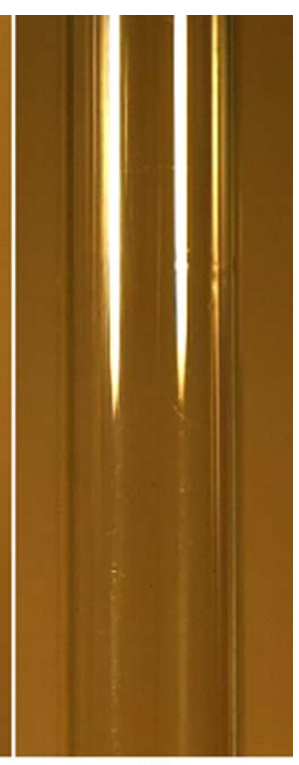

b)
Fig. 8. Glass gravity heat pipe inner diameter - $13 \mathrm{~mm}$, working fluid ethanol: a) Evaporation section b) Condensation section.
In the figure 9 are shown evaporation and condensation sections of glass gravity heat pipe with inner diameter $22 \mathrm{~mm}$ and ethanol working fluid. In the figure $9 \mathrm{a}$ is shown mixed pool and film boiling, where the bubble boiling is creating in whole evaporation section and film boiling creation on the bottom and then rise up to the top of the evaporation section. In the figure $9 \mathrm{~b}$ is not so good shown the film condensation but the film condensation of the working fluid was observed only in the right hand side heat pipe wall kind.

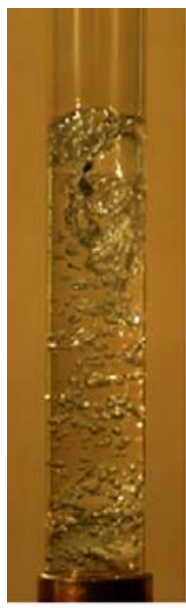

a)

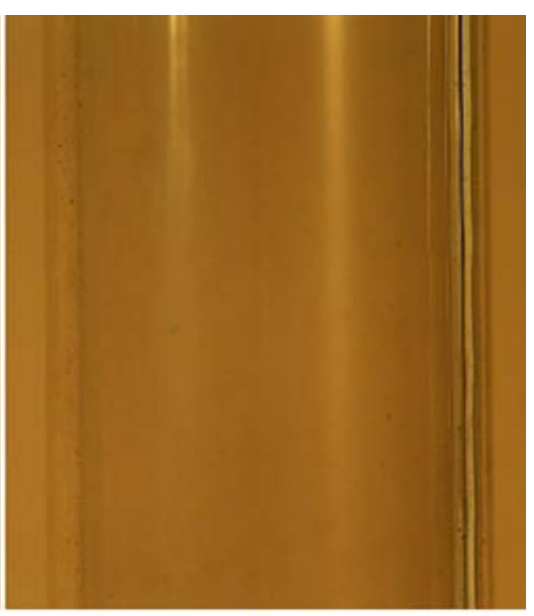

b)
Fig. 9. Glass gravity heat pipe - inner diameter $22 \mathrm{~mm}$, working fluid ethanol: a) Evaporation section b) Condensation section.

In the figure 10 are shown evaporation and condensation sections of glass gravity heat pipe with inner diameter $13 \mathrm{~mm}$ and fluorinert FC 72 working fluid. In the figure $10 \mathrm{a}$ is shown pool boiling of the working fluid in whole evaporator section. In the figure $10 \mathrm{~b}$ is shown film condensation of the working fluid. Condense of working fluid flown down throughout entire inner surface heat pipe wall.

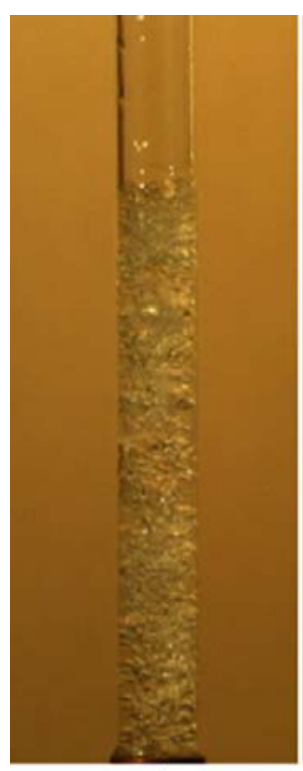

a)

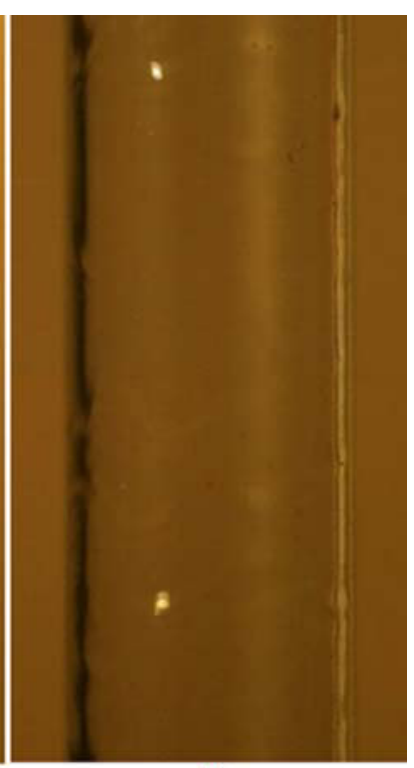

b)
Fig. 10. Glass gravity heat pipe - inner diameter $13 \mathrm{~mm}$, working fluid fluorinert FC 72: a) Evaporation section b) Condensation section. 
In the figure 11 are shown evaporation and condensation sections of glass gravity heat pipe with inner diameter $22 \mathrm{~mm}$ and fluorinert FC 72 working fluid. In the figure 11 a) is shown pool boiling of the working fluid in whole evaporator section. In the figure $11 \mathrm{~b}$ is shown the same film condensation of the working fluid as in the figure $10 \mathrm{~b}$. Condense of working fluid flown down throughout entire inner surface heat pipe wall.

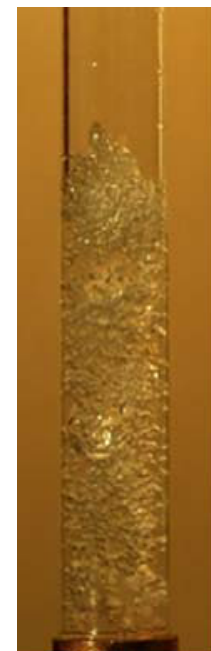

a)

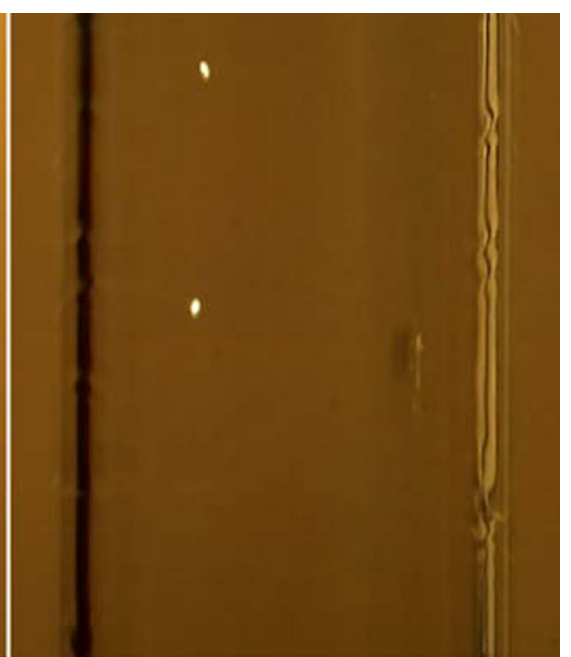

b)
Fig. 11. Glass gravity heat pipe - inner diameter $22 \mathrm{~mm}$, working fluid fluorinert FC 72: a) Evaporation section b) Condensation section.

\section{Conclusions}

Aim of this experimental work was flow visualization of various working fluid kinds in the gravity heat pipe and working fluid flow comparison considering to different inner diameter of heat pipe.

The experiment with various working fluid show that the investigated working fluids in heat pipe have various boiling and condensation regimes. At water heat pipe was observed film boiling and dropwise condensation regimes, at ethanol heat pipe was observed pool boiling and film condensation but the film condensation wetting only one side inner surface of the heat pipe wall, at the fluorinert FC 72 heat pipe was observed pool boiling and film condensation fully wetting entire inner surface of the heat pipe wall.

The experiment with different diameter dimensions show that the heat pipe dimeter dimension have not influence on the condensation regime but have influence on the richness of the flowing down condensate. Experiment show that the with the changing heat pipe diameter from small to big the boiling regime can change from pool boiling to mix of pool boiling and partially film boiling. Other findings of the experiment is that the boiling regime at heat pipe with the bigger diameter occur only in the evaporator section and at the heat pipe with smaller diameter occur in evaporator and partially at the adiabatic section.
This work is supported by the financial assistance of the project APVV - 15-0778 "Limits of Radiative and Convective Cooling through the Phase Changes of Working Fluid in Loop Thermosyphon".

\section{References}

1. A. S. Sundaram, A. Bhaskaran, J. of El. Cool. and Therm. Cont., 1, 15-21, (2011)

2. D. Ray, P. Kew, Heat pipes, fifth eddition (Elseviere, Oxford, 2006)

3. P. Dunn, D. Ray, Heat Pipes, 4th Edition, (Pergamon Press, Oxford, 1994)

4. L. J. Orman, AIP Conf. Proc., 1608 (2014)

5. L. J. Orman, EPJ Web of Conf., 67 (2014)

6. S. Liu, J. Li, Q. Chen, Flow Measur. and Instrum., 18, 216 - 222, (2007)

7. http://handbooks.swep.net/RefrigerantHandboo k/chapter 06/Pages/6.2-Boiling-Regimes.aspx

8. R. Nosek, M. Holubčík, Š. Papučík, Sci. World J., 2014, 487549, (2014)

9. M. Čarnogurská, M. Př́hoda, J. Molínek, J. of Mech. Sci. and Tech., 25 (11), pp. 2935-2941, (2011)

10. T. Brestovič, N. Jasminská, R. Pyszko, M. Lázár, M. Puškár, Measurement: J. of the Inter. Measur. Confed., 72, 3380, pp. 52-60, (2015)

11. http://ltcm.epfl.ch/files/content/sites/ltcm/files/s hared/import/migration/COURSES/TwoPhaseF lowsAndHeatTransfer/lectures/Chapter 7.pdf

12. R. Lenhard, J. Jandačka, AIP Conf. Proc., 1558, 2138-2141, (2013)

13. R. Lenhard, K. Kaduchová, Š. Papučík, J. Jandačka, EPJ Web of Conf., 67, 02067, (2014) 